\title{
“¿Condenados a la tierra?” Representaciones y propuestas en torno al "problema mapuche", 1900-1920
}

\author{
"Condemned to the land?" Representations and proposals \\ around the "Mapuche problem," 1900-1920
}

Francisco Cádiz Villarroel*

\section{RESUMEN}

Este artículo se propone analizar las diversas visiones sobre los mapuche y su relación con la "civilización", en este caso "lo chileno" y lo que ello signifique. Usando fuentes oficiales, provenientes de las memorias de diversos ministerios, y artículos de revistas especializadas que produjeron discursos sobre los mapuche, se realiza un análisis desde la perspectiva de los estudios del colonialismo de asentamiento (Settler Colonialism), que nos permitan engarzar esa óptica de análisis con la producción intelectual elaborada en nuestra época de estudio, situada entre 1900 y 1920. Respecto de la propiedad de la tierra y su relación con los mapuche, se concluye que, para los intelectuales de la época, aquellos no se encontraban preparados para ser dueños de su tierra y debían ser educados para hacerlas productivas, entre otras soluciones.

\section{SUMMARY}

This article's purpose is to analyze the different views on the Mapuche and their relationship with "civilization," in this case, "Chilean," and what this means. Using official sources, from the memoirs of various ministries, and articles from specialized journals that produced discourses on the Mapuche, an analysis is made from the perspective of the Settler Colonialism studies. The latter allows us to link this analysis perspective with the in-
Palabras clave: colonialismo de asentamiento, chilenización, ocupación territorial, mapuche.
Keywords: settlement colonialism, Chileanization, territorial occupation, Mapuche.

* Chileno. Licenciado en Historia, Profesor de Historia y Geografía, Universidad de Concepción, Chile. Estudiante del Programa de Magíster en Ciencias Sociales, Universidad de la Frontera, Chile. ORCID: https://orcid.org/0000-0002-3795-441X. E-mail: fcadizvillarroel@gmail.com 
“¿Condenadosalatierra?”Representacionesypropuestasentornoal“problemamapuche” | Cádiz

tellectual production produced in our period of study, located between 1900 and 1920. Regarding land ownership and its relationship with the Mapuche, we conclude that, for the intellectuals of the time, the Mapuche were not prepared to own their land and required education to make it productive, among other solutions. 
A fines del siglo XIX se produce la reocupación de Villarrica a manos del ejército de Chile, lo que pone fin al territorio de "La Frontera", como un espacio de contacto y conflicto entre mapuche, colonos (chilenos y extranjeros) y las autoridades chilenas, al menos formalmente. Con este hecho se concreta la unidad territorial de Chile, algo que en el contexto argentino de "Conquista del Desierto" (y chileno) deriva en el fin de las divisiones territoriales, al someterse a las autoridades centrales “y a un único sistema legal y productivo” (Quijada, 1999: 684).

Considerando las diferencias culturales y las creencias de las elites, luego de producida la ocupación emergen preguntas que tienen como nodo central saber qué hacer con los ocupantes de esas tierras. Para poder responder esa interrogante resulta indispensable conocer la manera en que tales ocupantes eran observados por el resto de la sociedad. Ante estas preguntas, la motivación presentada por Gabriela Nacach nos interpela:

"América Latina funcionó como un laboratorio para observar cómo, en un mismo período, y hasta muchos decenios más, se dieron prácticas a nivel racial —en pensamiento y acción-, diferentes y homologables según los casos, tanto desde procesos genocidas como de aculturación compulsiva a la vida 'civilizada' de los pueblos indígenas" (Nacach, 2009).

Las mencionadas prácticas se ligan al saber intelectual de la época, que validó la clasificación entre "nosotros" y "ellos", adjudicando valores de superioridad y exclusión, junto a prácticas políticas ligadas a esa dicotomía a diversos actores sociales.

Por ese motivo las palabras de Nacach se convierten en una inspiración para revisar algunos escritos sobre cómo eran observados los mapuche durante el periodo de 1900 a 1920, los cuales, para efectos de este estudio, se concentraban en el espacio comprendido entre el rio Biobío y la provincia de Valdivia, donde los diversos autores analizados realizaban sus apreciaciones.

Partiendo de estas concepciones, en las siguientes páginas se realiza un análisis de las representaciones sobre los mapuche que es posible encontrar en diferentes fuentes escritas de la época, especialmente en textos de misioneros y memorias ministeriales, elaboradas a principios del siglo XX. El criterio temporal es arbitrario y deter- 
minado por las posibilidades de acceso a las fuentes, basados en la distancia temporal desde el término "oficial" de la ocupación de "La Frontera" (1883).

Este estudio adopta una visión crítica sobre los escritos mencionados, cuestionándose, por ejemplo, la labor misionera en tanto preocupada de "cuidar a los mapuche", idea defendida por ejemplo por Jorge Pinto:

"Para los capuchinos, la desaparición o asimilación del mapuche a la 'chilenidad' habría ser fatal: si eso ocurría, nada podría justificar su presencia en el sur; como tampoco si se mostraba a un indígena incapaz de civilizarse o ajustarse a las condiciones de vida que se esperaba de ellos, cuando quienes gobernaban el país asumieron que el Estado debía librarlos de la 'barbaridad' en que vivían" (Pinto, 2015: 50).

Las tensiones plasmadas en el texto anterior, como la absorción de los mapuche por la "sociedad mayoritaria", continúan en la actualidad. Una muestra de ello se da en Maldonado y Del Valle, quienes revelan las representaciones prejuiciadas más comunes sobre los mapuche en la prensa, las que derivan de un monoculturalismo que sobrevalúa positivamente lo chileno por sobre lo mapuche. Como señalan los autores sobre los mapuche, "aparecen en los medios cuando se trata de "conflictos" y, sólo excepcionalmente, cuando se trata de acontecimientos que escapan a este campo representacional" (Maldonado y Del Valle, 2013: 286).

Para realizar el análisis propuesto para este artículo nos servimos de autores que se adscriben con posturas relacionadas al colonialismo de asentamiento, entre otras posturas críticas. En los apartados siguientes, el artículo continúa con un análisis de conceptos teóricos relevantes para este estudio, profundizando luego en los análisis discursivos, mediante su contrastación con fuentes de la época, para finalizar con las conclusiones del estudio.

\section{Antecedentes teóricos}

Observando el proceso postocupación de "La Frontera", en lo teórico tienen relevancia los conceptos de "subalternidad", "hegemonía", "colonialismo" y “representación”, aplicados al pasado histórico. 
El primero de ellos, a grandes rasgos pretende que "ciertas políticas promovidas por el Estado-nación [...] tendier[a]n a lograr que los grupos indígenas pasaran a convertirse en sectores subordinados" (Salomón, 2011: 547). Fue un proceso por medio del cual diversas agencias estatales e iniciativas privadas hicieron que algunos grupos poblacionales perdieran su capacidad de resistencia, lucha y subsistencia, cobrando importancia en ese proceso las tierras y la movilidad espacial, y agregando luego elementos de dominación cultural, espiritual, judicial, entre otros.

La pérdida de poder de unos y la concentración de poder en otros es clave en la subalternización. Para Ricardo Salvatore, dichas cuotas desiguales de poder generan que, quienes dominan, "construyen diversas categorías subalternas" o de dominados (Salvatore, 2010: 19). En esa situación destaca que la subalternización cruza y tensiona las relaciones entre los actores, los que no reaccionan pasivamente a su subordinación, gracias a su utilización de diversos repertorios de acción. La hegemonía, en segundo lugar, tiene ribetes culturales y sociales, ligados en primer lugar a la idea de "civilización versus barbarie" como discurso de las elites, que invoca un estado temprano de la sociedad, mientras la otra representa la forma más alta de existencia moral para la humanidad, atribuible a la elite misma (Burkitt, 2002: 136).

Norbert Elias, autor relevante en torno al concepto de "civilización", la vincula a un cambio de comportamiento, ligada a la "autoconciencia" y favorecida por procesos de centralización estatal, monopolio y remoción de la violencia por parte del Estado, favoreciendo así un cambio en las relaciones de poder y clases sociales que deriva en dominación y subordinación. Consecuencia de lo anterior es la "pacificación interna de la población", asentada en un balance de poder/relaciones, cuyo fin es no incurrir en excesos desestabilizadores, lo último apoyado en la interdependencia, solidaridad e inclusión (Burkitt, 2002: 137-142).

Este "proceso de civilización" conduce a una hegemonía de la sociedad. Ella es la aceptación de la dominación en cuanto "interiorización de la ideología dominante” (Kottak, 2006: 320). Si bien mencionamos el control de la violencia por parte del Estado como fundamental, la hegemonía no se restringe a ese componente, ya que incorpora 
"la construcción de nuevos significados y prácticas, por la interacción de varios tipos de agentes y las cambiantes alianzas y experiencias de clase" (Silverman, 2010: 400), manteniéndose la triada coerción/consentimiento/dominación, cuya forma, es construida a través de instituciones (...) de la sociedad civil" (Silverman, 2000: 401).

Tomando la relación entre elites y subalternos un carácter dialogante, al menos en esa idea de imposición consensuada, en el que ambos grupos "comparten por lo menos algunos signos y formas culturales, las cuales son impuestas, internalizadas, reformuladas, y simultáneamente apropiadas y contestadas, dándoles diferentes 'acentos' o significados" (Lagos, 1993: 58).

La imposición de hegemonía por medio de la subalternización facilita el uso y aplicación del concepto de "colonialismo". En autores como Patrick Wolfe, en su vertiente de "colonialismo de asentamiento" o "settler colonialism", funciona bajo una "lógica de eliminación" y ocupación permanente, en la cual:

"El objetivo final (...) es eliminar a las sociedades nativas de su tierra y reemplazarlas con colonos, eso no significa que los últimos aborígenes debían morir (...) con el tiempo la lógica de eliminación (...) se transmuta en diferentes modalidades, discursos y formaciones institucionales" (Kaomea, 2014: 127).

Profundizando en la "lógica de eliminación", ella incluye una serie de estrategias para lograr su objetivo: el desplazamiento, evangelización, secuestro, "chilenización", etc., expresiones de violencia sobre las que no hay mayores cuestionamientos morales, basadas en los ideales de civilización versus barbarie y superioridad racial ${ }^{1}$, y exculpándose en su actuar al eliminar culturas y ocupar territorios poco "usados" (en términos de transformación del territorio), ocultando los modos de uso y ocupación de sus habitantes originales.

1 "La historia humana fue imaginada como un proceso evolutivo, que comenzaba en un pasado remoto como una etapa de salvajismo, y esta se movió inevitable e inexorablemente a través de varias etapas de barbarie hasta alcanzar la civilización" (Domosh, 2002: 185; Anderson, 2002 y Edmonds 2010: 8). 
Desde la investigación social actual, para la zona en estudio no se utiliza explícitamente la idea de "colonialismo de asentamiento", siendo más recurrente su denominación como "colonialismo", que nos dice:

"El mapuche posterior a la ocupación pasó a representar una sobrecarga para un ideal nacional unitario basado en la supremacía europea. Todo esto se cristalizó fuertemente en los imaginarios institucionales y cotidianos, haciendo del cuerpo mapuche -identificado por sus rasgos faciales, por su historia familiar, por su procedencia territorial o por su apellido - una alegoría del estigma que inferioriza (...) También los saberes mapuche fueron proscritos (...) fueron leídas por el ojo colonial chileno y argentino como pruebas de inferioridad" (Alvarado, 2017: 128).

En la cita, el colonialismo va de la mano con una apreciación negativa sobre los mapuche, lo que los "racializa", concepto que vincula elementos mencionados para generar visiones negativas sobre los mapuche, esta vez con elementos de "identidad nacional chilena versus mapuche", con un cariz violento, racista y sexista (Tijoux y Palominos, 2015) .

En este escrito se entiende que la expropiación/despojo de tierras por parte de "lo chileno" y la justificación cultural prejuiciada es relevante para "hacer inferior" lo mapuche. Forma una ecuación en favor de los ocupadores de facto de ese territorio, tanto estatales como particulares. Prueba de ello se aprecia en las leyes y legislaciones ad-hoc, que entregan las tierras a quienes cumplen condiciones preestablecidas, unos "derechos legales" con el objetivo de tener una “jurisdicción espacial uniforme" por parte estatal (Mohr, 2003: 60, Blomley, 2011: 206).

Fruto de lo anterior, las legislaciones, por su parcialidad, no disminuyen las tensiones sociales o territoriales, generando incluso divisiones basadas en la "legitimación" de formas modernas de apropiación y trabajo de la tierra, por sobre formas tradicionales de posesión, volviéndose así el espacio y su relación con la ley en favorecedores o entorpecedores de la relación cultural que se desarrolla con la tierra (Mohr, 2003), por ejemplo, a través de mapas e interpretaciones sobre los mismos (Craib, 2000). 
Aplicando lo hasta aquí planteado emerge la "continuidad colonial" (Alvarado, 2016), que surge a raíz de la expropiación del territorio, al ocuparlo el Estado y los civiles Winkas, justificada en ficciones legales y argumentativas (Ugarte, Fontana y Caulkins, 2017), que reflejan y practican el racismo ${ }^{2}$. Justifica este último término la práctica colonial desarrollada por el Estado chileno hasta el momento de escribir estas líneas, en la que se observa que:

"Ninguna reacción que hemos visto en los últimos días es natural o espontánea. Emerge de la normalización del desprecio. He ahí la clave del racismo. El racismo es el instrumento ideológico de quien coloniza para perpetuar su poder, su capital forjado no en base al esfuerzo sino al despojo y la desposesión del otro, su posición en la estructura. El racismo es el aceite que engrasa el colonialismo chileno, por lo tanto, su presencia es constante y necesaria" (Alvarado, Antileo y Pairican, 2018: 5).

En esa declaración se establece la vinculación de colonialismo y racismo como base del despojo, cuya materialización más reciente es la muerte de comuneros mapuche durante procesos de recuperación de tierras.

Reavivando estos procesos de recuperación territorial la diada "civilización/barbarie" o "indio bueno/indio malo", al evidenciarse tácticas diferentes para recuperar tierras: la institucional y la de comunidades que actúan en sus territorios y que resisten el modelo extractivo auspiciado por el Estado chileno, que controla y mina la posibilidad de "otorgar derechos políticos vinculados a la autodeterminación de los pueblos" (Alvarado, Antileo y Pairican, 2018: 5).

Estas prácticas estatales las podemos vincular con un "racismo institucionalizado" (Maya, 2009), con formas más sistemáticas, permanentes y continuas. Una forma "cotidiana" de visibilizar estos racismos es a través del "prejuicio étnico", el cual incluye una serie de

2 La definición operativa que usaremos de "racismo" es la de Van Dijk (2002), que lo identifica como un "sistema societal complejo de dominación fundamentado étnica o racialmente, y su consecuente inequidad" (Van Dijk. 2003: 192). Se funda en una visión prejuiciada y no comprensiva sobre el resto, minusvalorando lo ajeno o distinto: "Nosotros sobre Ellos" (Ibíd.), e inculca una serie de características positivas en el primer polo de la díada. 
generalizaciones y opiniones erradas sobre un grupo social o étnico, y se manifiesta en un abanico amplio de expresiones y de conducta (Quilaqueo, 2005).

Finalmente, uniendo los conceptos anteriores de "colonialismo", "racialización", "hegemonía", entre otros, es necesario mencionar el de "representación”, siguiendo a Roger Chartier:

"La representación, en primera instancia, es aquello que hace que se asemeje el signo con la cosa; en segunda instancia, si la representación iguala a la cosa a través del signo, también trae consigo su significante (la muestra), que paradójicamente se encuentra ausente pero presente en esa relación signo-cosa" (Barrón, 2010: 51).

La apropiación es el paso clave de la representación, pues es "un espacio retórico en el que alguien (el representador) impersona a otro (el representado)" (Rosas, 2014: 288), restando características a lo que se quiere representar, uniformando y exteriorizando su recreación, dando lugar a prejuicios y a una falta de apertura cognitiva para mejorar la comprensión sobre lo que se quiere explicar. La representación vinculada al lenguaje prejuiciado, "cuyos significados se pueden esconder o disimular en la superficie” (Pilleux, 2005: 82), se repiten con cierta constancia histórica, para vehiculizar discursos racistas.

Los elementos mencionados, nos permiten realizar un análisis de la documentación de personas relevantes en lo religioso y ministerial en torno a los mapuche, lo que veremos en el apartado siguiente.

\section{Lo mapuche como "problema" en fuentes de la época}

Para los intelectuales de la época, la raza se conceptuó como "una diferencia biológica que era esencial e inmutable. Las diferentes razas llegaron a entenderse como productos de creaciones completamente separadas" (Anderson y Perrin, 2007: 19; Howard, 2009). Esta idea se aprecia incluso en los elementos mezclados entre ellas, como notamos en la siguiente descripción racial de los mestizos y los rasgos mapuche que presentan como rasgo inmutable y diferenciador:

"El primero [mestizos pobres de los campos en la zona de "La Frontera"] tiene la cabeza relativamente grande, la nuca ancha, las facciones pesadas, la quijada fuerte y cuadrada, la nariz carnosa, la 
boca grande, el labio largo, el tinte un poco bronceado, pero raras veces muy obscuro; tiene el cuerpo desarrollado, el tronco largo, el pecho alto y arqueado, y es dispuesto a la corpulencia, los brazos y las piernas son cortas y fornidas; las manos y los pies también cortos, pero anchos.

Se distingue especialmente por lo corto del talón, lo grueso del tobillo y pierna, sin que esté diseñada la pantorrilla. Casi todos estos caracteres son los de los mapuche, e indican que este elemento ha dejado sus huellas en la población actual" (Latcham, 1912: 306).

La valoración de esas cualidades "mapuche" denotan un sesgo del autor, que evidencia en sus palabras la inferioridad de los mapuche que circulaban por la Araucanía, al acentuar los marcadores raciales, limitar sus posibilidades de acción y presentarlos como con menores capacidades que otros pueblos. Latchman se basa en mediciones comparativas antropométricas entre diversos pueblos y razas, según los cánones científicos de la época, dando lugar a expresiones prejuiciadas y etnocéntricas, sobre razas salvajes o el uso o no de calzado, entre otras.

“Tanto en el hombre como en la mujer el dedo pulgar de los pies es prensil y muy bien desarrollado, lo que es característico en todas las razas que no usan calzado. El indio, cuando sube a caballo, no estriba sobre la punta de los pies sino sobre el pulgar únicamente (...)

Las piernas de los hombres son generalmente cortas y de muy buena conformación huésica y articular; pero conservan los caracteres comunes a las razas salvajes, son muy delgadas, a tal punto que no guardan proporción con el resto del cuerpo” (Matus, 1912: 378).

El paso siguiente de esos discursos es la "eliminación de las diferencias" por medio de la asimilación forzada, valiéndose de medios avalados por el Estado: políticos, culturales y territoriales, considerando que ya se había usado la violencia militar coercitiva:

"Es tiempo ya de incorporar definitivamente la raza araucana a la población nacional.

Entregada al vicio, ampara las depredaciones que sufre constantemente la frontera, y sirve de pretexto todas las especulaciones de mala fe. Solo se ha mantenido al amparo soberano de la ley que 
prohíbe a los particulares adquirir las propiedades de los indígenas, con notable detrimento del desarrollo agrícola del sur (...)

El Gobierno continuará velando solícito por la civilización, pero esta situación debe terminar en beneficio de los intereses de los particulares" (Ministerio de Relaciones Esteriores, Culto i Colonización, 1901b: 130).

La cita anterior valida la incorporación de los mapuche, al postular como positivo apartarlos de los vicios y "malas costumbres" gracias al influjo de la civilización, paso por el cual también se protegerían de los abusos de chilenos de malas intenciones, al encontrarse "habilitados" culturalmente para defenderse, como "chilenos", de las acciones negativas de sus mismos connacionales.

Profundizando en lo anterior, la relación entre raza araucana, falta de progreso y lógicas economicistas explicita creencias sobre que unas "razas" son superiores a otras, usando para aquello argumentos como los siguientes: "la historia humana fue imaginada como un proceso evolutivo que comenzaba en un pasado remoto como una etapa de salvajismo, y esta se movió inevitable e inexorablemente a través de varias etapas de barbarie hasta alcanzar la civilización" (Domosh, 2002: 185, Anderson, 2002). Esa evolución se nota en las crónicas misioneras, como en la siguiente del Padre Luis Mansilla:

"Vemos con satisfacción de nuestra alma, que los araucanos, que ya van entrando por la senda que nos marca la religión cristiana, se conforman con su humilde modo de vivir y dicen con sentidas frases: 'Si nuestros padres hubieran sido instruidos en la luz del santo Evangelio, que nos hace comprender cuán sublime es la civilización cristiana, no nos encontraríamos en el oscurantismo, faltos de bienes intelectuales y materiales como nos hallamos actualmente. Porque ellos, a la vez que hubieran cultivado su inteligencia, también habrían sabido dar a sus campos un grandioso impulso, multiplicando sus haciendas, proporcionándonos lo suficiente para nuestra subsistencia; y no estaríamos como nos hallamos, desprovistos de lo necesario para nuestra mantención en la actualidad"' (Mansilla, 1904a: 250).

En el discurso del misionero se articulan la eficacia de la religión con la educación y el trabajo, en tanto elementos guías para la "civi- 
lización" de los mapuche. Lo planteado se observa en que, desde la perspectiva del misionero, los mapuche, gracias a la acción misionera, poseen la capacidad para dominar las fuerzas de la naturaleza.

Considerando lo anterior, cuestionamos el uso utilitario e interesado de Mansilla sobre el impacto de su labor, porque no sabemos si ese testimonio es real o un artilugio retórico, lo que deslegitima su valor como pieza de interpretación necesaria.

Retomando esa idea del "dominio de la naturaleza", esa habilidad fue un resorte concentrado en los colonos europeos (y por deriva en la acción misionera europea), los cuales eran tratados como "los otros útiles" que riegan ese bienestar sobre la región, según las fuentes:

"En cada uno de esos centros se ve, a la simple observación, la influencia del trabajo inteligente y metódico venciendo palmo a palmo al bosque secular y dominando a la naturaleza con el esfuerzo irresistible de las leyes que reglan el progreso humano.

No solo ha venido con el colono un nuevo obrero a la sociabilidad chilena, sino que aquél trae también consigo el espíritu que domina en los viejos países de Europa, donde el trabajo es la ley suprema" (Ministerio de Relaciones Esteriores, Culto i Colonización, 1901a: 12).

La acción beneficiosa externa, plasmada por medio de la inmigración, es fructífera para el país y la zona, al transformar el paisaje y explotar las riquezas ocultas del territorio, como se indica:

"Entregar a la producción nacional los terrenos inexplorados del sur, escampar metódicamente sus extensos bosques, aprovechando los grandes valores en madera que ellos contienen, utilizar la fuerza hidráulica de los numerosos ríos y corrientes de agua que cruzan el territorio, abrir canales y practicar la irrigación de nuestros campos, y explotar las enormes riquezas que encierran en metales nuestras cordilleras y en peces y mariscos el Océano que baña nuestras dilatadas costas" (Ministerio de Relaciones Esteriores, Culto i Colonización 1902: 220).

Con su acción transforman al país y a la zona, en una visión extractivista de recursos naturales, siguiendo el discurso de las "ventajas relativas" en las cuales se espera obtener la riqueza y el tan anhelado progreso 
de "La Frontera" y el país, por medio de la explotación de recursos y la transformación productiva de la zona, en busca de recursos económicos.

Esta transformación productiva tiene muchas formas de acción, siendo una de ellas la de generar el "hábito de industria", que genera sujetos "autodisciplinados" gracias a la biopolítica y su correlato en la higiene (Anderson, 1995), y a la educación como una práctica, desprendiéndose de esta acción un "sujeto colonizado" (Fife, 2001:261), al menos en el plano ideal, según se desprende del siguiente comentario:

"Si los poderes públicos quisieran interesarse en la civilización de la parte semibárbara de nuestros indios, podrán llevarla a cabo con pocos tropiezos. Para ello la mitad del trabajo está hecho, pues no se necesitaría convencer a los indígenas de la ventaja que reporta la vida civilizada y de la importancia de la instrucción: conocen ellos las ventajas, y podría agregarse que las palpan" (Fraunhauls, 1914: 12).

En esta creación del sujeto colonial o subalternizado, la agencia se debe tomar en cuenta; por ejemplo, al darse cuenta los mapuche de las posibilidades de defensa y negociación que ellos mismos llevaban a la práctica para defender su tradición y modos ancestrales de existencia, para lo que "usaban las armas del enemigo", como se lee en el siguiente testimonio:

"Han notado que los de su raza que saben leer y escribir, que han constituido familia, como lo exige la costumbre civilizada, acatando las leyes nacionales, hallan muchas facilidades para conservar y defender sus tierras y no son víctimas de las inicuas explotaciones e irritantes abusos que la mayor parte de ellos sufren" (Fraunhauls, 1914: 12).

Ante el beneficio de adoptar el proceder del dominador y ejercer su capacidad de agencia, el autocontrol y la disciplina son vitales, al tener que ocultar o dejar de practicar costumbres consideradas degradantes por los dominadores, las que fueron vistas como una muestra patente del salvajismo mapuche y la "cultura que mantenían vivos" (Smithers, 2009: 270), volviéndose necesario para los misioneros acabar con esas costumbres, como se aprecia en la siguiente cita:

"Si no fuera, Sr. Ministro, por la poligamia que reina todavía en gran parte de nuestros araucanos, siendo esta piedra que les estorba marchar con certeros pasos por la senda de la civilización, podría- 
mos decir llenos de placer, que casi todos nuestros indios se encontrarían preparados para entrar en el camino que les llevase a su completa conversión, al cristianismo y a la civilización" (Mansilla, 1904b: 381).

Por ello se proponen los misioneros y el Estado "reformar los roles de género y las prácticas sexuales de los indígenas para asegurar un orden social patriarcal y la propagación de la civilización occidental en los espacios de colonialismo de asentamiento" (Smithers, 2009: 270). El efecto deseado de esa reforma es lograr la transformación de los mapuche en cristianos y ciudadanos:

"Lo que impide, Señor Ministro, a una parte, aunque pequeña, en porción de los adultos y ancianos de muchas tribus que desean hacerse cristianos, es la poligamia, pareciéndoles imposible determinarse a abandonar a las mujeres que han tomado como esposas, según su costumbre, y casarse con una, como lo determinan todas las leyes, considerándolas con igual derecho a todas ellas; y al mismo tiempo, cada una de estas se cree ser la designada, para esposa, según las dotes de que se ve adornada, sin ceder ninguna su derecho. De allí resulta la dificultad para proceder al bautismo de tales personas, dejándolas hasta que comprendan lo dictaminado por las leyes sobre esta materia. Muchos de ellos, después de hacerles reflexiones sobre la ignorancia en que se encuentran, y alumbrados con las luces de la gracia, se resuelven, de común acuerdo, a abandonar ese modo salvaje de vivir y abrazar lo ordenado por la religión católica, para ser hombres amantes a Dios y a la patria" (Mansilla, 1904c: 390).

Para los misioneros, las prácticas sexuales de los mapuche son una traba en su proceso de civilización. Este problema se inserta dentro del debate llevado a cabo entre los investigadores sobre la sexualidad de los indígenas, quienes actualmente afirman que la civilización y los roles de género están íntimamente ligados y codeterminados: "las sociedades civilizadas tenían que estar pobladas por hombres varoniles y mujeres femeninas" (Domosh, 2002:186), los roles se establecen en relación a los parámetros de actividad física, autocontrol y bienestar de la sociedad, como se explicita en la siguiente cita:

"Las mujeres civilizadas eran pasivas y delicadas; eran las cuidadoras de la familia y las guardianas de la moral y los sentimientos de la sociedad. Los hombres civilizados eran varoniles, es decir, eran au- 
tocontrolados, racionales y proveedores del bienestar económico y físico de las mujeres y los niños" (Domosh, 2002: 186).

La acción misional evidencia la necesidad de llevar a la práctica estas prerrogativas, como se desprende de los comentarios de misioneros que se adentraron en las reducciones y el territorio de la Araucanía. En estos testimonios emerge el choque de visiones entre mapuche y misioneros sobre diversas prácticas culturales, por ejemplo, el vestuario:

"Como no hay, en nuestro país, una ley que determine la forma de vestido que debe usarse, es muy natural, que el indígena permanezca en su antigua costumbre, dándole ésta, hasta cierto punto, un aliento para creerse como independiente en sus inveteradas costumbres que todavía le hacen salvaje" (Mansilla, 1904c:391).

O sobre la higiene y salubridad, aunque con un claro sesgo de los misioneros:

"Llamó especialmente mi atención en el aseo que noté en casi todas las viviendas, a pesar de que el indio de aquella región es por lo general sucio y ha perdido todos sus hábitos de aseo. Los antiguos Historiadores nos hablan de que eran muy limpios, que se bañaban dos o tres veces al día. Hoy esto no ocurre. Las únicas que conservan este hábito todavía son las mujeres, que lo hacen diariamente a la hora de la siesta (11 a 1 P.M.)" (Matus, 1912: 376).

En este texto se evidencian los roles de género y las diferencias de género de los mapuche, siendo este un elemento perfectible de mejorar, ya que, en su opinión, en el estado actual al que Matus se refiere, la condición masculina está desmejorada, por lo tanto, es posible mejorarla con la ayuda del Estado y los misioneros.

\section{Propiedad de la tierra y los mapuche}

El tema de la tierra, su posesión y utilización, es un elemento conformador de las sociedades en las que se produce la ocupación colonialista, y nuestra zona en estudio no escapa a ello. Esto se observa en los documentos analizados, en los que la delimitación y conformación de la propiedad es un proceso conflictivo, al haber muchos actores interesados. Dicha situación vehiculiza la aparición de numerosos prejuicios hacia ellos. 
Una muestra de lo anterior aparece en las fuentes del Ministerio de Relaciones Exteriores, Culto i Colonización, en las cuales la legislación protectora hacia el indígena se ve como un estorbo, de acuerdo con lo declarado por ellos, ya que el mapuche:

"Entregado al vicio, ampara las depredaciones que sufre constantemente la frontera, y sirve de pretexto a todas las especulaciones de mala fe. Solo se ha mantenido al amparo soberano de la ley que prohíbe a los particulares adquirir las propiedades de los indígenas, con notable detrimento del desarrollo agrícola del sur" (Ministerio de Relaciones Esteriores, Culto i Colonización, 1901b: 130).

La violencia y maltrato vivido por los mapuche, según el texto sería culpa de ellos mismos. Una forma de poner coto a esa situación es el llamado a adecuar la legislación sobre tierras y radicación de inmigrantes para dar cuenta las situaciones que se producen en los territorios.

La explicación del acento en la legislación de tierras se debe a que una mejor distribución de la tierra, tanto fiscal como privada, otorgará al Estado la "conciencia territorial" adecuada para dinamizar su gestión y cuidar las tierras fiscales de las usurpaciones de los particulares, además de disminuir las tensiones hacia los mapuche, facilitando que aprecien lo bueno de la civilización:

"Es imprescindible proceder ya a la mensura general de los terrenos fiscales, y liquidar los derechos del Estado y los de los particulares a fin de conocer con exactitud la propiedad fiscal y poder entregarla a la colonización sin los temores y zozobras que ocasionan los litigios y cuestiones judiciales. Son muy pocas las extensiones de suelo fiscal no amparadas o usurpadas por particulares" (Ministerio de Relaciones Esteriores, Culto i Colonización,1901b: 129).

Para ello se crea la "Inspección Jeneral de Tierras y Colonización", representante del fisco en las disputas y defensa de la tierra fiscal. En términos simples, el problema indígena, en la concepción de este Ministerio, tiene relación con: 1) lo necesario de su pronta radicación en un terreno "legalizado" y 2) la legislación proteccionista del Estado en cuanto a impedir la venta de las tierras indígenas otorgadas a ellos. La visualización de estos problemas aparece, por ejemplo, en los remates, cuando se constituye efectivamente la propiedad fiscal para remates 
u otras contingencias. Todas estas situaciones impiden una transición positiva hacia la civilización de los mapuche, ya que son sometidos a situaciones de violencia física y cultural, las que pueden ser apreciadas como naturalizadas, al mostrar los mapuche una inacción que posibilita esos abusos:

"Al amparo de los derechos que las leyes conceden a los indígenas araucanos se han creado intereses cuantiosos que amagan la propiedad fiscal. Por otra parte, es tiempo ya de incorporar definitivamente la raza araucana a la población nacional.

Entregada al vicio, ampara las depredaciones que sufre constantemente la frontera, y sirve de pretexto para todas las especulaciones de mala fe. Solo se ha mantenido al amparo soberano de la ley que prohíbe a los particulares adquirir las propiedades de los indígenas, con notable detrimento del desarrollo agrícola del sur (...)

El Gobierno continuará velando solicito por la civilización, pero esta situación debe terminar en beneficio de los intereses de los particulares y del Estado" (Ministerio de Relaciones Esteriores, Culto i Colonización, 1901b: 130).

Las situaciones mencionadas más arriba afectan los intereses económicos, al inhibir la inversión y el "progreso". La depredación de tierras y los vicios indígenas, según las fuentes de la época, alteran el progreso agrícola deseado para el sur de Chile, donde se supone que la colonización extranjera debía producir un incremento de ésta. Esta actividad es detenida por problemas cuya base es el mapuche y la utilización que de él se hace, o la perfidia de éste para defraudar al Estado, según el Ministerio.

La caracterización de los indígenas como estorbo a la consolidación de la propiedad estatal de la tierra, se complementa con el siguiente comentario:

“Con posterioridad a la ley de 18 de enero de 1893, la prohibición de adquirir terreno de indígenas se extiende desde el sur del Bio-Bio hasta el límite austral de la República; de modo que el fenómeno que se presencia actualmente en el sur es el de la propiedad cultivada por nacionales, escudados por el indígena vicioso, degenerado i tinterillo, tristes cualidades que han llegado a ser su carácter ordinario, por influencia del medio en que ha desarrollado su 
existencia desde veinte años a esta parte" (Ministerio de Relaciones Esteriores, Culto i Colonización, 1901b: 134).

Este fragmento es valioso, porque en él se desliza cierta responsabilidad estatal por la situación cultural y económica en la que se ha llevado a cabo la vida mapuche pospacificación. Eso no impide al Ministerio resaltar que la situación de los mapuche se ve acentuada (y reiterada nuevamente) por sus vicios, por tener contacto con chilenos poco honestos que los llevan a la degeneración y hace inútil en la práctica la legislación protectora. De esta situación existen muchas apreciaciones en el material utilizado, como la que a continuación se presenta:

"La mayor parte de las veces los indígenas vienen a reclamar nulos y problemáticos derechos, impulsados por los que, explotando sus terrenos, alimentan a poco costo los vicios de los indígenas, y así explicarse US. esa romería constante de indígenas y especialmente las últimas solicitudes de exclusiones de los terrenos puestos en remate por el Departamento de su digno cargo" (Ministerio de Relaciones Esteriores, Culto i Colonización 1901b: 134).

Entre funcionarios estatales existen visiones que contrastan lo ya esbozado, al no separarse totalmente del sesgo prejuiciado. Una muestra de lo anterior aparece en 1908, cuando se valora positivamente la entrega de títulos de propiedad, superándose las representaciones en las que se indicaba que los mapuche eran culpables del acaparamiento de tierras, por su "indiferencia" o por el abuso de los colonos, ya que al "ser poseedores (...) de grandes extensiones de tierras, flojos y sin ninguna cultura, se contentaban con mantenerse de lo que les producía un pequeño retazo que malamente cultivaban" (Irribarra, 1908: 224), situación que superan al tener su título y una serie de derechos ligados.

Para los funcionarios estatales, que los mapuche sean dueños de sus tierras facilita que los mismos no sean víctimas de abusos o sean utilizados para defraudar al fisco en materia de tierras. Dicha impresión se liga con la influencia "negativa" de la cultura y tradiciones mapuche que les impedían acceder a la civilización:

"Es un hecho generalmente aceptado que la comunidad entre los indígenas y los cacicazgos, son causa de que permanezcan en barbarie sin progresar a pesar de las medidas civilizadoras empleadas a su favor. (...) 
La división de un terreno dado a una reducción entre las diversas familias que la componen tiene por consecuencia, la conclusión del cacicazgo i de la comunidad entre ellos, y esta división tan benéfica ha dejado de efectuarse desde que los Protectores no disponen de ingenieros a los cuales encomendarlas" (Urrutia, 1908: 14).

Extrañamente, para insertar a los mapuche en la civilización se plantea la radicación, en tanto defensa de los indígenas para que no sucumban ante la civilización y desaparezcan, a pesar de todas las opiniones prejuiciadas y negativas emitidas anteriormente:

"Pues es un fenómeno natural que, en la lucha secular de la civilización contra la barbarie, debe sucumbir ésta: que se defiendan solos, no hay razón para ampararlos con leyes especiales.

Los que así piensan preconizan el derecho del más fuerte, divinizan la justicia por sí misma, consagran el homicidio, el incendio, etc., y olvidan que todos los pueblos cultos registran en sus códigos disposiciones protectoras de los que no disciernen.

La defensa de los indígenas se impone, es el complemento de su radicación" (Irribarra, 1908: 224).

Avanzando un poco aparece el tema de su implementación y de cómo lograr una defensa efectiva de los mapuche a través de la radicación, sin que ello genere su desaparición forzosa. En 1901 se pensaba que una forma de hacerlo era mediante la constitución de la propiedad indígena, con la que "vendría por sí sola la incorporación del araucano a la masa del pueblo chileno" (Ministerio de Relaciones Esteriores, Culto i Colonización, 1901b: 21), a través de su radicación como "colonos con derechos iguales a los demás", de forma pausada, hegemónicamente mediante la inmersión cultural, y desprendiéndose así de la creencia de que el proceso de incorporación sería de forma violenta.

Otro tema que causa escándalo en los funcionarios ministeriales y religiosos es la ya mencionada poligamia, como instancia de inferioridad y degradación de su humanidad: "Sometido a una legislación especialísima que le degrada consagrando la poligamia, y que, al mismo tiempo, le envilece matando en él los nobles impulsos de la iniciativa, por el estado de comunidad absoluta en que vive" (Ministerio de Relaciones Esteriores, Culto i Colonización, 1901b: 21). 
Hasta aquí es posible dar cuenta de que la propiedad efectiva era una solución beneficiosa para todas las partes, porque facilitaría la inserción de los mapuche en la sociedad chilena. Gracias a esto, establecemos que existen múltiples soluciones al problema de la tierra y los mapuche, siendo la trampa de aquellas la vinculación o base en la tierra, lo que da sentido a observarlos como "los condenados de la tierra", al centrar en esa tierra el problema, fijando de paso posiciones estáticas de alterización, blanqueamiento y asimilación forzada del mapuche, en cuanto a "atarlo" a la tierra y las tradiciones que se cree poseen o a las capacidades que se cree "bueno" que desarrollen.

Uno de los proyectos notables que vinculan esas líneas, es el de 1908 sobre "Constitución y defensa de la propiedad indígena", el cual no fue aprobado y nos ofrece una rica observación de lo mencionado. En primer lugar, este proyecto define lo que es un indígena en su artículo primero: "Son indígenas los aborígenes del territorio situado al sur de la provincia de Arauco que conserven el idioma, los apellidos paterno o materno de su raza y siquiera en parte las costumbres" (Irribarra, 1908: 257), es decir, estandariza e impide los cambios y acomodos de los que la cultura mapuche hace gala hasta el día de hoy. En segundo lugar, notamos la ambivalencia señalada, al proyectarse la entrega de hijuelas de terreno, con base individual y personal, girando en torno al "jefe de familia", evidenciándose que, si bien se valora su cultura y tradiciones para ser merecedores de hijuelas de terreno, la mayor o menor cantidad de tierras será determinada de forma "patriarcal" y con criterios de inclusión/exclusión marcados por el grado de "civilización", como la educación formal "chilena", servicio militar, uso de medicina chilena, entre otros. Si no se cumplen esos criterios viene el castigo pecuniario, físico o de control de desplazamiento, como se establece a continuación:

"Art. $5^{\circ}$. Para determinar la cabida que debe asignarse al jefe de familia, las comisiones tomarán en cuenta:

$1^{\circ} \mathrm{Si}$ sabe leer y escribir.

$2^{\circ}$ El grado de civilización de la familia.

$3^{\circ}$ La calidad del terreno que ocupa y el tiempo que haya habitado en él.

$4^{\circ}$ La cantidad de terreno que tenga cultivado, los cierros que haya construido y las limpias que haya hecho. 
$5^{\circ}$ El número de animales que los miembros de la familia posean en propiedad.

$6^{\circ}$ La conducta observada por el jefe de la familia.

$7^{\circ}$ Haber constituido la familia conforme a la lei de Registro Civil. (...)

Art. 24. Los indígenas quedan obligados a enviar a la escuela a sus hijos mayores de diez años hasta que aprendan el idioma español, las primeras letras y un oficio manual, siempre que funcione uno de dichos establecimientos a menos de cinco kilómetros.

La infracción de este precepto será penada con multa de diez pesos o diez días de prisión.

Art. 25. El servicio militar es obligatorio para los varones indígenas de veinte años de edad. Lo prestarán por un año continuado y en los cuerpos de ingenieros militares.

Art. 26. Todo indígena está obligado a vacunarse, bajo pena de veinte pesos o veinte días de prisión, lo cual se aplicará al padre de los menores de edad" (Irribarra, 1908: 257 y 261).

Paradójicamente, en esta pieza se argumenta que estas medidas tienen por fin confirmar que "los derechos reales de los indígenas son inembargables" (Irribarra, 1908: 259), en base a prohibiciones que perpetúan la inamovilidad de posesión territorial:

"Art. 11. Se prohíbe a los indígenas enajenar terrenos y celebrar contratos de hipoteca, anticresis o arrendamiento. Igualmente se prohíbe a los particulares adquirir por cualquier motivo terrenos de indígenas.

Son nulos y de ningún valor los contratos que contravengan a esta ley" (Irribarra, 1908: 259).

Con esto se busca generar una transformación cultural en favor de la asimilación cultural de los mapuche. Se apoya esta idea en que la propiedad individual permite deshacer los lazos identitarios y tradicionales del mapuche, desatando a los sujetos de sus tradiciones y favoreciendo una nueva adscripción dentro de la nación de ciudadanos y cristianos. Para ello, los mapuche deben ser guiados, ya que es necesario hacer del mapuche "un ciudadano progresista y patriota que acarree caudales nuevos de energía y entusiasmo para el bien- 
estar y el progreso de nuestra patria querida, Chile" (De Amberga, 1917: 80).

En la concepción capuchina, la agricultura se convierte en la solución paliativa del problema indígena, siendo la escuela el lugar adecuado para enseñarla, como se menciona: "De imprescindible necesidad son anexos de escuela agrícola a los internados. El indígena tiene poco terreno y no hay esperanza de que pronto alcance más extensión; pero su terreno es capaz de mejoras; y trabajado intensamente produce mucho más" (De Amberga, 1913: 35).

Una fase superior en efectividad a la mera escuela es la labor realizada por los internados, en los que es posible "moldear corazones y voluntades" de los niños mapuche. Como se indica, "es preciso sacar al niño araucano de su ruca, de su ambiente, para que aprenda pronto y bien el castellano; para que en el íntimo contacto con el niño blanco asuma las mil ideas que forman la vida civilizada y que el campo no puede prestar" (De Amberga, 1913: 35). Explicitando el cierre de posibilidades sobre las potencialidades mapuche, al reducirse su accionar a la agricultura o lo técnico, subsumiendo otras posibilidades.

Se debe destacar la noción salvadora de la enseñanza misionera sobre los mapuche, con la idea de que "haríamos de él un ciudadano laborioso, honrado y patriótico" (De Amberga, 1917: 65). Con ello se los "desmapuchiza" en pos de la civilización, en vías de "cristianizar" primero y volver "chileno" después, quitando todo valor a sus tradiciones y cultura.

Por ello, las declaraciones del Padre De Amberga manifiestan una utilización que podríamos consensuar basada en ideales del "colonialismo de asentamiento", en tanto lógica de eliminación, al avalar el secuestro y la educación en internados, entre otras prácticas. Esta afirmación debe matizarse con su preocupación por la situación de cambio de matriz económica de los mapuche, originada por la acción misional que evita la pobreza y abusos hacia los mapuche:

“ ¿Podemos permitir que los cien mil araucanos, con sus cualidades nobles, generosas, que necesitan solamente educación y desarrollo, degeneren completamente en la miseria a que se ven reducidos? Yo no quiero cansar con declamaciones tristes e inútiles sobre la situa- 
ción y los sufrimientos de los indígenas, sino exponer un medio, un paliativo para salvar lo que es posible" (De Amberga, 1917: 65).

Es posible que estas declaraciones tengan una segunda intención, considerando que pudieron estar influenciadas por la búsqueda de sustento para la labor misional; por tanto, pudo realizarse una adecuación del relato.

La acción misional y los proyectos de ley mencionados no tuvieron los efectos esperados. El acoso sobre las tierras mapuche se mantuvo después de establecidas las radicaciones y mercedes de tierra. Es así como, entre 1919 y 1923, se acercó a las oficinas del Protector de Indígenas y de la Comisión Radicadora un número aproximado de doce mil indígenas, a los que "se les ha atendido en sus peticiones de amparo por abusos cometidos contra ellos, y sus solicitudes de nuevas radicaciones, procurando, en todo momento, concluir con las desavenencias que continuamente se originan entre los indios que viven en comunidad, por medio de convenientes particiones" (Ministerio de Relaciones Exteriores. Culto y Colonización, 1923: 838).

Ante situaciones de ese tenor se planteaban las mismas soluciones una y otra vez, acentuando el problema sobre los mapuche en vez de revisar el contexto que los rodeaba, de modo que, desde ese ojo sesgado, solo situaba los problemas en el mapuche, lo condenaba a la tierra y a empaparse de "civilización" chilena, lo que en la práctica significaba su desaparición por asimilación, como bien se aprecia en la siguiente cita:

"La solución está en civilizarlos, distribuyendo escuelas en los campos, obligándolos al servicio militar, impeliéndoles á dejar las costumbres ya inaceptables de la poligamia, y haciendo desaparecer á la vez el cacicazgo. Nada contribuye más á esos objetos que la escuela, como también la constitución de la propiedad individual del indígena, que ya él mismo reclama, dando con ello un signo evidente de progreso" (Ministerio de Relaciones Exteriores, Culto i Colonización Nacional, 1910: 470).

\section{Reflexiones finales}

Al principio de este artículo nos propusimos analizar diversos discursos y fuentes documentales, originados principalmente en fuen- 
tes ministeriales y religiosas, para analizar su visión sobre los mapuche entre 1900 y 1920 . Se dedujo que la pregunta que rondaba en las elites de la época tenía relación con qué hacer con ellos luego de producida la ocupación estatal. Estas observaciones dan luces sobre la visión que los autores analizados tenían acerca de los mapuche y lo que esperaban que sucediera con ellos al pasar los años. Las respuestas establecen que se esperaba su asimilación por diversas vías a "lo chileno", y la educación y la propiedad privada de la tierra fueron los principales mecanismos pensados para lograr esa asimilación, en tanto desaparición de los mapuche. Estas situaciones nos permiten afirmar, siguiendo a Galtung, que los mapuche sufrieron violencia estructural, con ribetes en lo económico, simbólico y político, en base a la posesión o desposesión de tierras (Goicovic, 2015: 36-37). La violencia estructural, en los textos revisados, se patentiza en la utilización interesada de lo mapuche y su visibilidad para mantener cierto control sobre su educación y adoctrinamiento en lo católico, entre otros aspectos, lo que se aprecia en los misioneros bávaros, según señala Jorge Pinto, como una tensión entre cumplir su misión cristiana y abandonar a los mapuche.

Nos adentramos en la defensa contra esa expoliación por parte de diversos actores, tratando de ver un patrón de protección que paradójicamente excluye a los mapuche de su cultura tradicional, en pos de insertarlos dentro de "lo chileno", con lo que en la práctica no se les defendió de esa expoliación material y cultural, reafirmando en cambio la violencia estructural.

Como ya se mencionó la labor misionera, aquí nos explayaremos sobre ella, diciendo que se hace evidente mostrar avances de su labor religiosa y representarse a sí mismos interna y externamente como esforzados trabajadores que merecen la subvención y mantención estatal en los territorios, realzando la ambivalencia de su labor. Giran sus memorias y artículos entre diversas posturas complementarias: dar cuenta de las costumbres que aún conservan los mapuche, señalar los obstáculos para su cristianización y realzar su posterior ciudadanización e integración definitiva como "cristianos-ciudadanos-chilenos". En esa lógica, no descartan utilizar la "ventriloquía" para hacer hablar a los mapuche sobre los beneficios de la acción misional y la protección como preparación para la "civilización” y la integración. 
Sobre las visiones ministeriales, notamos que se centran en una habilitación ciudadana en tanto "dueños" de tierras, con "títulos" que deben ser protegidos, por ejemplo, mediante la educación, habilitándose así para vivir dentro de lo "chileno".

Las representaciones sobre los mapuche, tanto de religiosos como de autores ministeriales y otros, se complementan para perpetuar la exclusión sobre los mapuche, ya sea para protegerlos o habilitarlos, desconociendo el valor de quienes intentan "objetivar", basados en los prejuicios raciales, científicos y culturales de la época.

Estableciendo vínculos con el presente, creemos que las fuentes usadas, al tener circulación dentro de esferas con amplio poder de masificar y adoctrinar estas visiones (misioneros y profesores, en el caso de la Revista Chilena de Historia y Geografía), se unen a otras producciones de los medios de comunicación que empiezan a configurar un discurso ajeno y exterior a lo mapuche: en relación con ellos, pero sin ellos.

Algunas preguntas que surgen de esta investigación se relacionan con la exclusión y el desarrollar una vinculación más explícita con el "colonialismo de asentamiento" y la "chilenización", a nivel teórico y práctico, usando el caso de los mapuche. Sobre estas perspectivas de investigación, es interesante enriquecer el utillaje conceptual, por ejemplo, aplicando explícitamente el concepto de "colonialismo de asentamiento", en cuanto se plantea: "problematizar los modos y lógicas de poder donde la representación de lo mapuche como raza inferior, o como sujeto minorizado, transforma la violencia y el tutelaje como principales formas de integración-exclusión y de gobierno" (Nahuelpán, 2013: 15).

Es necesario visibilizar y romper las lógicas que actúan inferiorizando a los mapuche y que naturalizan el que deban estar bajo el cuidado y la protección de alguien más, y su correlato que permea lo político, económico y social, pues, como se señala, "el colonialismo se halla internalizado en los cuerpos, las subjetividades y en nuestras contradictorias y heterogéneas identidades" (Nahuelpán, 2013: 15), lo que impide tener una relación de apertura y entendimiento de modo horizontal y comprensiva con los mapuche. Prueba de ello está en la pregunta del título al artículo, cuya respuesta, bajo el colonialismo de asentamiento, es clara y afirmativa, llevando a un destino aciago a los 
mapuche, ya que su implementación produjo una campesinización forzada (Bengoa, 2000), la que afectó a los mapuche de forma determinante, acelerando su migración a las ciudades, en donde fue claro que no escaparon de las lógicas de racialización y exclusión, como lo explican Alvarado y Nahuelpan.

\section{Referencias bibliográficas}

\section{Fuentes primarias}

\section{a) Publicaciones oficiales}

Irribarra, C. (1908). "Memoria del Protector de Indígenas de Valdivia i Llanquihue", en T. Urrutia. Memoria de la Inspección Jeneral de Colonización e Inmigración. Santiago de Chile: Imprenta i Encuadernación Universitaria de S.A. García Valenzuela, pp. 211-267.

Mansilla, L. (1904a). Las misiones franciscanas de la Araucanía. Costumbres araucanas, reminiscencias históricas y datos estadísticos relativos á la región en donde están ubicadas las Misiones de la Prefectura apostólica de Angol, por el Padre Luis Mansilla. Angol: Imprenta del Misionero Franciscano.

Mansilla, L. (1904b). "Memoria anual pasada al Señor Ministro de Culto por el Prefecto de Misiones R.P. Fr. Luis Mansilla sobre los trabajos de los misioneros en 1902", en L. Mansilla. Las misiones franciscanas de la Araucanía. Costumbres araucanas, reminiscencias históricas y datos estadísticos relativos á la región en donde están ubicadas las Misiones de la Prefectura apostólica de Angol, por el Padre Luis Mansilla. Angol: Imprenta del Misionero Franciscano, pp. 380-388.

Mansilla, L. (1904c). "Memoria anual pasada al Señor Ministro de Culto por el Prefecto de Misiones R.P. Fr. Luis Mansilla sobre los trabajos de los misioneros en 1903", en L. Mansilla. Las misiones franciscanas de la Araucanía. Costumbres araucanas, reminiscencias históricas y datos estadísticos relativos á la región en donde están ubicadas las Misiones de la Prefectura apostólica de Angol, por el Padre Luis Mansilla. Angol: Imprenta del Misionero Franciscano, pp. 389-398.

Ministerio de Relaciones Esteriores, Culto i Colonización (1901a). "Memoria de la inspección Jeneral de Tierras i Colonización”, en 
Ministerio de Relaciones Esteriores, Culto i Colonización. Memoria del Ministerio de Relaciones Esteriores, Culto i Colonización presentada al Congreso Nacional en 1901. Santiago de Chile: Imprenta Nacional.

Ministerio de Relaciones Esteriores, Culto i Colonización (1901b). “Sección Colonización”, en Ministerio de Relaciones Esteriores, Culto i Colonización. Memoria del Ministerio de Relaciones Esteriores, Culto i Colonización presentada al Congreso Nacional en 1901. Santiago de Chile: Imprenta Nacional.

Ministerio de Relaciones Esteriores, Culto i Colonización (1902). "Memoria de Relaciones Esteriores, Culto i Colonización”, en Ministerio de Relaciones Esteriores, Culto i Colonización. Memoria de Relaciones Esteriores, Culto i Colonización presentada al Congreso Nacional de 1902. Santiago: Imprenta Cervantes.

Ministerio de Relaciones Exteriores, Culto i Colonización (1910). Memoria de Relaciones Exteriores Culto i Colonización presentada al Congreso Nacional. El $1^{\circ}$ de Junio de 1910. Santiago: Imprenta Cervantes.

Ministerio de Relaciones Exteriores, Culto i Colonización (1923). Memoria de Relaciones Exteriores, Culto i Colonización, Noviembre 1919-Junio 1923. Santiago: Sociedad Impresora i Literaria Universo.

Urrutia, T. (1908). Memoria de la Inspección Jeneral de Colonización e Inmigración. Santiago de Chile: Imprenta i Encuadernación Universitaria de S.A. García Valenzuela.

\section{b) Artículos y conferencias}

De Amberga, J. (1913). "Estado intelectual, moral y económico del araucano", en Revista Chilena de Historia y Geografía, $\mathrm{N}^{\circ} 11$, pp. 5-37.

De Amberga, J. (1917). "Agricultura araucana", en Revista Chilena de Historia y Geografía, 으 25, pp. 54- 80.

Fraunhauls, S. (1914). Defensa de los araucanos: conferencia dada en la Biblioteca Nacional. Santiago: Imprenta de San José.

Latcham, Ricardo (1912). "Los elementos indígenas de la raza chilena", en Revista Chilena de Historia y Geografía, ํㅜ 8, pp. 303-329.

Matus, L. (1912). "Vida y costumbre de los indios araucanos", en Revista Chilena de Historia y Geografía, $\mathrm{N}^{\circ}$ 8, pp. 362-410. 


\section{Fuentes secundarias}

a) Artículos y capítulos de libros

Alvarado, C. (2016). "Silencios coloniales, silencios micropolíticos. Memorias de violencias y dignidades mapuche en Santiago de Chile", en Aletheia, Vol. 6, $\mathrm{N}^{\circ} 12$, pp. 1-17.

Alvarado, C. (2017). “ $¿ Q u e ́$ pueden temer los winka si los mapuche nos unimos?' Raza, clase y lucha sindical mapuche. Santiago, 1925-1980", en CUHSO, Vol. 27, № 2, pp. 121-151.

Alvarado, C., E. Antileo y F. Pairican (2018). "El desprecio por las vidas mapuche", en Le Monde Diplomatique, $\mathrm{N}^{\circ} 202$, pp. 4-5.

Anderson, K. (2002). "The racialization of difference: Enlarging the story field", en The Professional Geographer, Vol. 54, N 1, pp. 25-30.

Anderson, K. y Perrin, C. (2007). “'The miserablest people in the world': Race, humanism and the Australian aborígenes", en The Australian Journal of Anthopology, Vol. 18, $\mathrm{N}^{\circ}$ 1, pp. 18-39.

Anderson, W. (1995). "Excremental colonialism: Public health and the poetics of pollution", en Critical Inquiry, Vol. 21, $\mathrm{N}^{\circ} 3$, pp. 640-669.

Barrón, M.A. (2010). "El baile de los 41: la representación de lo afeminado en la prensa porfiriana", en Historia y Grafía, $\mathrm{N}^{\circ} 34$, pp. 47-76.

Blomley, N. (2011). "Cuts, flows, and the geographies of property", en Law, Culture and the Humanities, Vol. 7, $\mathrm{N}^{\circ}$ 2, pp. 203-216.

Burkitt, I. (2002). "Civilization and ambivalence”, en British Journal of Sociology, Vol. 47, N 1, pp. 135-150.

Craib, R. (2000). "Cartography and power in the conquest and creation of New Spain", en Latin American Research Review, Vol. 35, $\mathrm{N}^{\circ} 1$, pp. 7-36.

Domosh, M. (2002). "A 'civilized' commerce_gender, 'race', and empire at the 1893 Chicago Exposition", en Cultural Geographies, Vol. 9, $\mathrm{N}^{\circ}$ 2, pp. 181-201.

Fife, W. (2001). "Creating the moral body: Missionaires and the technology of power in early Papua Nueva Guinea", en Ethnology, Vol. 40, N 3, pp. 251-269.

Edmonds, P. (2010). “Unpacking settler colonialism's urban strategies: Indigenous peoples in Victoria, British Columbia, and the 
transition to a settler-colonial City", en Urban History Review/Revue d'historie urbaine, Vol. 38, N² 2, pp. 4-20.

Goicovic, I. (2015). "Campos conceptuales, perspectivas de análisis y ciclos históricos en el espacio del movimiento mapuche (1870-1990)", en J. Pinto (ed.). Conflictos étnicos, sociales y económicos Araucanía 1900-2014. Santiago de Chile: Pehuén, pp. 19-48.

Howard, D. (2007). "Development, Racism, and Discrimination in the Dominican Republic", en Development in Practice, Vol. 17, $\mathrm{N}^{\circ}$ 6, pp. 725-738.

Kaomea, J. (2014). "Education for elimination in Nineteenth-Century Hawai'i: Settler Colonialism and the native hawaiian Chief's Chidren's boarding school", en History of Education Quaterly, Vol. 44, $\mathrm{N}^{\circ} 2$, pp. 123-144.

Lagos, M. (1993), 'We have to ask': hegemony, diverse experiences, and antagonistic meanings in Bolivia", en American Ethnologist, Vol. 20, $\mathrm{N}^{\circ}$ 1, pp. 52-71.

Maldonado, C. y Del Valle, C. (2013). “Medios de comunicación y narrativas hipertextuales lógicas del desplazamiento del 'conflicto mapuche' al espacio virtual", en Andamios, Vol.10, $\mathrm{N}^{\circ}$ 22, pp. 283-303.

Maya, L.A. (2009). "Racismo institucional, violencia y políticas culturales. Legados coloniales y políticas de la diferencia en Colombia", en Historia Crítica, Vol. 39, Suplemento 1, pp. 218-245.

Mohr, R. (2003). "Law and identity in spatial contests", en National Identities, Vol. 5, $\mathrm{N}^{\circ}$ 1, pp. 53-66.

Nacach, G. (2009). “Cuestión de paradigmas: conquista, representaciones y pensamiento racial en la Pampa y la Patagonia argentina (1860-1915)", en Ë̈, Vol.1, N², pp. 1-24. Disponible en: https://issuu.com/eajournal/docs/conquista-pensamiento-racial-pampa-patagonia, revisado el 28-X-2021.

Nahuelpán, Héctor (2013). “Las 'zonas grises' de la historia mapuche. Colonialismo internalizado, marginalidad y políticas de la memoria", en Revista de Historia Social y de las Mentalidades, Vol. 17, $\mathrm{N}^{\circ}$ 1, pp. 11-33.

Pilleux, M. (2005). "El Prejuicio de los chilenos en contra de la etnia mapuche", en M. Pilleux. Contextos del Discurso. Valdivia: Facultad de Filosofía y Humanidades-Universidad Austral, pp. 79-86. 
Pinto, J. (2015). “Los orígenes del conflicto Estado-pueblo mapuche en el siglo XX", en J. Pinto (Ed.), Conflictos étnicos, sociales y económicos Araucanía 1900-2014. Santiago de Chile: Pehuén, pp. 49-90.

Quijada, M. (1999). “La ciudadanización del 'indio bárbaro'. Políticas oficiales y oficiosas hacia la población indígena de La Pampa y la Patagonia", en Revista de Indias, Vol. 59, № 217, pp. 675-704.

Quilaqueo, D. (2005). "Residentes de la ciudad de Temuco: estigma del prejuicio étnico en el discurso mapuche”, en M. Pilleux. Contextos del Discurso. Valdivia: Facultad de Filosofía y Humanidades-Universidad Austral, pp. 64-78.

Rosas, M.I (2014). "De esclavos a ciudadanos y malentretenidos. Representaciones del negro en el discurso jurídico colombiano del siglo XIX", en HISTOReLo, Vol. 6, No 12, pp. 271-301.

Salomón, C. (2011). "Proceso de subalternización de la población indígena en Argentina: Los ranqueles en La Pampa, 1870-1970”, en Revista de Indias, Vol. 71, N 252, pp. 545-570.

Silverman, M. (2001). "Custom, courts and class formation: constructing the hegemonic process through the petty sessions of a Southeastern Irish Parish, 1828-1884", en American Ethnologist, Vol. 27, $\mathrm{N}^{\circ} 2$, pp. 400-430.

Smithers, G. (2009). “The 'pursuits of the Civilized Man': race and the meaning of civilization in the United States and Australia, 1790-1850s", en Journal of World History, Vol. 20, $\mathrm{N}^{\circ} 2$, pp. 245-272.

Tijoux, M.E. y Palominos, S. (2015). “Aproximaciones teóricas para el estudio de procesos de racialización y sexualización en los fenómenos migratorios de Chile", en Polis, Vol. 14, N 42, pp. 247-275.

Ugarte, M., M. Fontana y M. Caulkins. (2017). “Urbanisation and Indigenous dispossession: rethinking the spatio-legal imaginary vis-á-vis the Mapuche nation", en Settler Colonial Studies, Vol. 9, $\mathrm{N}^{\circ}$ 2, pp. 187-206.

Van Dijk. T.A. (2002). "Discurso y racismo", en Persona y Sociedad, Vol. 16, $\mathrm{N}^{\circ} 3$, pp. 191-205.

\section{b) Libros}

Bengoa, J. 2000. Historia del pueblo mapuche (siglo XIX y XX). Santiago de Chile: Lom Ediciones. 
Kottak, C. (2006). Antropología Cultural. Madrid: McGraw-Hill.

Salvatore, R. (2010). Subalternos, derechos y justicia penal. Ensayos de historia social y cultural Argentina 1829-1940. Buenos Aires: Gedisa.

Van Dijk. T.A. (2003). Dominación étnica y racismo discursivo en España y América Latina. Barcelona: Gedisa. 